\title{
Online Informative and Educational Resources on the Benefits That a Lifestyle Aimed at the Primary Prevention of Cancer May Also Provide for General Health
}

\author{
Aldo T. Marrocco \\ I. C. “G. Toniolo", Pisa, Italy \\ Email: aldo marrocco@yahoo.it \\ Received 13 July 2015; accepted 4 August 2015; published 7 August 2015 \\ Copyright (C) 2015 by author and Scientific Research Publishing Inc. \\ This work is licensed under the Creative Commons Attribution International License (CC BY). \\ http://creativecommons.org/licenses/by/4.0/

(c) (i) Open Access

\section{Abstract}

To find stimuli for getting young students interested in the primary prevention of cancer and a healthy lifestyle, internet resources have been searched that may motivate and facilitate this study. Teachers interested in teaching this subject can download for free and use them with the method felt as most appropriate; they consist of text, graphs, tables, images, quizzes and an interactive atlas. According to a personal experience, the use of these educational resources helps teachers in teaching and students in learning about cancer prevention. According to the World Health Organisation, cancer is a leading and growing cause of mortality with 10 and 14 million new cases worldwide respectively in $\mathbf{2 0 0 0}$ and $\mathbf{2 0 1 2}$. Several risk factors have been identified; if they are avoided, more than $30 \%$ of the cancers can be prevented. The five most important modifiable risk factors, among many others, are: smoking, alcohol, overweight, physical inactivity, low consumption of vegetables and fruit. Cancer may also have genetic causes or be related to certain infections that are more common in some areas than in others. According to several documents also quoted in this article, numerous behaviours that reduce cancer risk may, at the same time, help to prevent other important diseases. Some of the documents quoted here show the very great difference in cancer incidence and mortality rates often existing between different geographic areas. For example, prostate cancer incidence per 100,000 persons per year is 104.4 in New Zealand, and 3.9 in Chennai, India. Many studies found an increase over time in the incidence of certain cancer types in people that move from countries where their risk is low to countries where their risk is high, thus suggesting the important role of environmental changes and lifestyle. As an example of this, the risk of breast cancer among Hispanic women migrating to US increases with the duration of residence in the immigration country, and becomes up to 4 - 6 times higher after 3 or more generations. This provides an example of what can happen in transitioning countries as a consequence of some lifestyle changes, unless measures are taken. 
Keywords

Educational Resources, Teacher, Lifestyle, Cancer, Risk, Prevention, Migrants

\section{Introduction}

According to the World Health Organisation, cancer (C) is a leading and growing cause of morbidity and mortality, with respectively 10 and 14 million new cases worldwide in 2000 and 2012 [1] [2].

Several risk (R) factors of $\mathrm{C}$ have been identified and yet, according to the WHO, if these are avoided, more than $30 \%$ of new cases can be prevented [1]. The five most important avoidable or modifiable $R$ factors, but not the only ones, are: overweight, low consumption of vegetable and fruit, physical inactivity, smoking and alcohol [1]. Certain infections, radiations, urban and indoor air pollution also play an important role.

The aim of this paper is to present educational and informative resources for readers, and in particular for teachers interested in teaching about primary prevention of $\mathrm{C}$ in the school.

A presentation of informative and educational resources on cardiovascular primary prevention was published in March 2015 [3].

\section{Aims of the Teaching Unit}

To find stimuli for getting young students interested in the prevention of $\mathrm{C}$ and a healthy lifestyle, internet resources have been searched that may motivate and facilitate this study.

\section{Materials and Methods}

The informative and educational resources presented in this manuscript consist of text, graphs, tables, images, quizzes and an interactive atlas; they can be downloaded for free from the web.

Such resources can also be used by teachers, if they like and with the method felt as most appropriate, for helping students to understand how the $\mathrm{R}$ of $\mathrm{C}$ can be lowered.

According to several documents quoted in this article, avoiding $C R$ factors may, at the same time, prevent other diseases.

The discussion of this article is based exclusively on the documents quoted here.

The subject is very complex, and this paper may constitute an introduction to a more complete study. This article may stimulate further researches in the web; some criteria and tools may help students interested in the search of reliable documents on this subject [4].

\section{Discussion}

"Global patterns of Cancer Incidence and Mortality Rates and Trends" is the title of a document that shows the great differences regarding the rates that exist from a country to another [5]. For example, prostate cancer incidence per 100,000 persons per year is 104.4 in New Zealand, and 3.9 in Chennai, India [5].

The document also deals with both the reasons attributed to such differences and the favourable effects which screening programmes often have, or have had in the different countries [5]. Although early detection of $C$ is not among the aims of this paper, a WHO document on this subject is quoted [6].

"Global Cancer Statistics" is the title of a document that, inter alia, provides several graphs and data [7].

An I.A.R.C. document contains numerous atlases and graphs; some of them deal with the incidence of some Cs in several geographic areas and others with the future trends of this disease [8].

Through the interactive World Atlas of the Pulitzer Center, we may have a quick overview about the strongly differing incidence and mortality for the most important Cs [9].

The above mentioned documents may also provide awareness, e.g. about which Cs are or are becoming common in our country, what causes them and how the related Rs can be reduced (author's note).

Worldwide, lung $\mathrm{C}$ is worldwide the leading cause of death among males [7]. Its rates are rising in countries where smoking continues to increase or has just peaked. On the contrary, in countries where smoking has peaked earlier, lung $\mathrm{C}$ rates are decreasing in men and plateauing in women [5]. 
A document dedicated to colorectal $\mathrm{C}$ analyzes the changing rates in some countries and regions in relation to changes in their economy, life style, $\mathrm{R}$ factors. The benefits of screening activities are also reported [10]. As a general rule, colorectal $\mathrm{C}$ incidence is continuing to rise in economically growing countries as a consequence of the trend toward the adoption of a western lifestyle. In contrast its rates are stable or decreasing in long-standing economically affluent countries [10].

In Japan a sharp increase in the rates of colorectal C has been observed in the past, as shown in Figure 2 of the document [10]. This is attributed to diet changes, now more rich with animal food and fats that contributed to increased obesity in this country. This hypothesis is supported by the strong increase in colorectal C rates documented in the US among Japanese migrants, as a consequence of similar changes in lifestyle [10].

Among the Supplementary Data of an article [5], we can find and open the supplementary Figure 9 that shows the increasing prostate $\mathrm{C}$ rates in some countries, attributed to increased animal fat consumption, physical inactivity and obesity.

Breast $\mathrm{C}$ is, on a global scale, the leading cause of death among females [7].

A paper studies the influence of migration to US on the R of breast $\mathrm{C}$ among Hispanic women [11]. This $\mathrm{R}$ increases with the duration of residence in the US and after 3 or more generations it is 4-6 times higher than that of women just migrated from rural areas [11]. This observation is consistent with other studies that also found an increase over time of breast $\mathrm{C}$ incidence in women that move from countries where this $\mathrm{R}$ is low to countries where this $\mathrm{R}$ is high [11]. The paper also discusses the reasons that can be attributed to this increased $\mathrm{R}$.

A paper deals with the different incidence of $\mathrm{C}$ between Koreans born and living in South Korea, and those who immigrated to the US. The incidence of $\mathrm{C}$ exhibited by the latter is intermediate between those observed respectively in Korea and the US [12]. The $\mathrm{C}$ rates of colon, kidney and prostate in Koreans living in their native country are respectively $0.40,0.33,0.06$ compared to US whites; in Korean-Americans such rates are 0.76, 0.47, 0.25 . This example reflects an increased incidence of some Cs in Koreans migrated from their native land to a country where such Rs, in the general population, are higher.

The $\mathrm{C}$ rates of stomach, gallbladder and liver among Koreans living in their native country are respectively 9.8, 5.4, 8.7 times higher compared to US whites; in Korean-Americans such rates are 4.3, 2.9, 4.4 times higher. This last example reflects a decreased incidence of such Cs after the migration from the native land to a country where such Rs, in the general population, are lower.

The genetic homogeneity between Koreans living in their native country and Koreans migrated to the US, suggests the important role of lifestyle and environmental changes in causing such different $C$ incidence rates [12]. The document discusses extensively the changes in C R profile and its reasons [12].

The increased rates of $C$ in some sites of the body, observed after the migration from low- to high-risk areas, provides an example of what may happen in transitioning countries as a consequence of lifestyle changes. Such increases in $C$ rates can be prevented, provided that appropriate measures are taken [13].

"Occupation and cancer, follow-up of 15 million people in five Nordic countries" is the title of a wideranging document that provides a very large amount of data and graphs on $\mathrm{C}$ incidence for several categories of workers in the Scandinavian countries [14]. For example, the lowest standardized incidence rates for all malignant Cs exhibited among males are between 0.79 and 0.88 ; they have been observed in: domestic assistants, farmers, gardeners, forestry workers and teachers. The highest standardized incidence rates, between 1.20 and 1.48, have been observed in: chimney sweeps, waiters, tobacco and beverage workers [14]. The differences are even stronger when the incidence of $\mathrm{C}$ in certain particular parts of the human body are analysed. In males, for example, the ratio of mesothelioma is 4.74 among plumbers and 0.24 among farmers; the ratio of lip $\mathrm{C}$ is 2.27 among fishermen and 0.44 among administrators. The paper provides some explanations about the reasons attributed to such differences [14].

Some Cs are related to infections that can, e.g. affect the genes inside the cells, cause long-term inflammations, or suppress the immune system. The Rs of cervical and liver $\mathrm{C}$ are respectively increased by human papillomavirus, and hepatitis B and C; the Kaposi sarcoma has been linked to HIV infection [15].

A document deals with family $\mathrm{C}$ syndromes. Some types of $\mathrm{C}$ seem to run in certain families; this may depend on some R factors shared among the family members, such as smoking or obesity that increase the R of certain Cs. Sometimes an abnormal gene that has the potential to lead to a certain type of C can be inherited [16].

Genetic mutations are involved in all Cs; most of them occur during a single lifetime, whereas others are inherited from the parents, these latter are thought to be involved in $5 \%$ - $10 \%$ of $\mathrm{C}$ cases [17].

The presence of a mutation predisposes to a certain C but it does not necessarily mean that the person in ques- 
tion will develop this disease, and if this happens, the intensity of the symptoms may differ from a person to another [17]. The mutations that control the growth of the cells and the repair of damaged DNA are probably more linked than others with the $\mathrm{R}$ of $\mathrm{C}$.

Mutations linked with more than 50 hereditary C syndromes can be detected through genetic tests; clearly, their presence recommends taking precautions in order to keep as low as possible the $\mathrm{R}$ of the related $\mathrm{C}$ [17].

Information about family history as a R factor for colorectal $\mathrm{C}$ can be found through the website of the National Cancer Institute [18]. For this, just click on: > Find a Cancer Type (Colorectal Cancer), then >Colorectal Cancer Prevention, then >Genetics of Colorectal Cancer, and finally >Family History as a Risk Factor for CRC [18].

The relative $\mathrm{R}$ of colorectal $\mathrm{C}$ according to the family history has been calculated; this is 2.3 for first-degree relatives of an affected case compared with those without such family history, and 3.9 if this affected relative has been diagnosed before age 45 . The $\mathrm{R}$ is 4.3 if two or more first-degree relatives are affected [18].

In the website of the American Cancer Society, a document can be accessed that deals with the prevention of some Cs, entitled "ACS Guidelines for Nutrition and Physical Activity" [19].

From a page of the American Cancer Society it is possible to select a $C$ type and then to get information about, e.g. its $R$ factors, prevention, early detection, diagnosis, treatment and news from the research [20]. Selecting a $\mathrm{C}$ type from this website it is possible to read about particular $\mathrm{R}$ factors, e.g. exposure to arsenic, vinyl chloride and anabolic steroids for liver $\mathrm{C}$, exposure to asbestos for mesothelioma, and low fluid consumption for bladder C [20].

A page of the National Cancer Institute provides general information about the causes of C; selecting "Risk Factors", "Genetics" and "Cancer Prevention Overview" much information on such subjects can be accessed [21]. Among the $\mathrm{R}$ factors for $\mathrm{C}$ we also find, e.g. immunosuppression and chronic inflammation.

This last is a physiological reaction of the organism that is necessary until an injured tissue is healed. When the inflammatory process starts without being caused by any injury, or does not end after this latter is healed, then it is a case of "chronic inflammation" that over time may result in DNA damage and lead to C [21].

The I.A.R.C. Monographs contain critical reviews and evaluations concerning the $\mathrm{R}$ of $\mathrm{C}$ related to a wide range of agents to whom human beings are likely to be exposed [22]. The term "agent" encompasses, e.g. specific chemicals and mixtures of them, biological organisms, physical agents, behavioural practices. Several monographs deal with chemical agents, whereas others are dedicated to, e.g. shiftwork, high temperature frying, indoor combustions, solar radiation, radon and wood dust.

\section{Diet and Cancer}

According to a review, in 128 of 156 studies, fruit and vegetable consumption exhibited a significant protective effect against $C$ in many sites of the human body [23].

A diet that ensures adequate plasmatic levels of folate, $\mathrm{B}_{6}$ and $\mathrm{B}_{12}$ vitamins has been linked to a lowered $\mathrm{R}$ of breast C [24].

According to a WHO document, a daily intake not lower than $400 \mathrm{~g}$ of fruit and vegetables has the property of reducing the Rs of developing C, diabetes, obesity and heart diseases. This W.H.O. document specifies that potatoes, cassava and other tubers are not included in such category of fruit and vegetables [25]. From this webpage, it is possible to open "Expert report on diet, nutrition and the prevention of chronic diseases" [25].

Nearly half a million people have been followed during a European prospective investigation aimed at studying the relations between colorectal C R and nutrition, over a period that lasted 4.8 years [26].

According to this research, the comparison of groups with respectively the highest and the lowest meat consumption resulted in a hazard ratio of 1.57 [26]. Still according to this study, the comparison of groups with the highest and the lowest fish consumption, exhibited a hazard ratio of 0.69 .

The poultry intake did not significantly influence the hazard ratio [26].

According to the American Heart Association, the omega-3 fatty acids contained in fish and particularly in the most fatty ones, decrease R of arrhythmias, lower blood pressure and triglyceride levels, and slow the growth of atherosclerotic plaque [27].

For a more complete information, old and large predatory fishes, such as tuna and swordfish, may contain high levels of pollutants. Women that are, or plan to become, pregnant or are breast-feeding, and children should not eat such products; all other people are advised not to exceed in the intake of fish that may contain high levels of pollutants [19] [27]. 
According to a review, in several studies but not all, allium vegetable consumption is associated with a reduced C incidence; a protective effect has been observed in several sites of the body and particularly in the digestive apparatus [28].

A document of the National Cancer Institute provides further information about garlic and C prevention. The document also deals with the interference of this vegetable with several prescription drugs. Garlic acts as a blood thinner, therefore it should be avoided, e.g. in people that use blood thinners, in pregnant women, and before undergoing surgery [29].

According to a review, a 17\% reduction in the $\mathrm{R}$ of coronary heart disease has been observed among individuals who ate more than 5 servings a day of fruit and vegetables, compared to those that ate less than 3 servings a day [30].

A diet rich with fruit and vegetables, and in particular allium vegetables and non-citrus fruit, has exhibited a protective effect against hip osteoarthritis [31]. According to laboratory tests, diallyl disulphide, one of the bioactive compounds that originate from dietary garlic, inhibits the degradation of cartilage [31].

An F.A.O. manual entitled "Setting up and running a school garden" is based on experiences from all over the world. Its aim is promoting lifelong healthy eating habits and may help in teaching children how to grow healthy food and improve nutrition [32].

Producing vegetables and fruits for own consumption is notoriously regarded as a healthy practice that also implies physical activity. However, we must be careful if the environment is chemically or biologically contaminated; the titles of four articles regarding such problems [33]-[36] summarize their contents:

"Pollution Status of Pakistan: A Retrospective Review on Heavy Metal Contamination of Water, Soil, and Vegetables".

"Five keys to growing safer fruits and vegetables: promoting health by decreasing microbial contamination".

"Safely Using Produce from Flooded Gardens".

"Home Gardens and Lead. What You Should Know about Growing Plants in Lead-Contaminated Soil”.

\subsection{Obesity and Overweight}

In the US, overweight and obesity are deemed to contribute to one fifth of the deaths related to C [19].

"Obesity and Cancer Risk" is the title of a document of the National Cancer Institute [37]. Fat tissues produce excess amounts of estrogen; high levels of this hormone are linked to $\mathrm{C}$ in some sites of the body, e.g. breast and endometrium [37]. Obese people are likely to be affected by insulin resistance and chronic low level inflammation; both of them may increase the $\mathrm{R}$ of some Cs [37]. The document contains a list of Cs whose $\mathrm{R}$ is associated with obesity and provides explanations on the subject [37].

The $\mathrm{R}$ of gallbladder $\mathrm{C}$ is high in obese people. This is attributed to the higher frequency of gallstones observed in these people, which constitutes a strong $\mathrm{R}$ factor for gallbladder $\mathrm{C}$ [37].

The distribution of the body fat is also important; for instance, the Rs of pancreatic and colon $\mathrm{C}$ in men are strongly associated to abdominal obesity [37].

Obesity is an important R factor for osteoarthritis of knee and hand; 2.81 and 2.59 are the odds ratio calculated for the respective joints [38].

Many studies have found a link between obesity and R of age related cataract. In a few studies, even a low body mass index has been associated to a higher R, in these cases attributed to a poor nutritional status [39].

Obesity is strongly associated with a high intraocular pressure that is the most important $\mathrm{R}$ factor for glaucoma [39].

Considerable evidence supports the link between obesity and age related maculopathy [39].

According to most studies, there is a link between a high body mass index and R of retinopathy [39].

A WHO document provides general strategies for obesity prevention, e.g. the promotion of exclusive breastfeeding in infants, adequate intake of fruit and vegetables, limiting sugar-sweetened beverages, and an active lifestyle [2].

The Harvard School of Public Health provides a document entitled "Obesity Prevention Source"; here, particularly interesting is the link "Visit the Nutrition Source" [40].

\subsection{Physical Activity}

According to an American study, a vigorous physical activity practiced consistently is associated to a substantial 
reduction of breast $\mathrm{C} \mathrm{R}$ in post-menopausal women, provided that a stable weight is kept during adulthood. The odds ratio observed in these women is 0.42 [41].

A study, that involved more than a hundred thousand runners and walkers, tested the effects of physical activity in the reduction of diseases including $\mathrm{C}$. The study provides much information on the benefits regarding, e.g. kidney C prevention, cardiovascular health, incidence of cardiac arrhythmias, stroke, and R factors such as hypertension, hypercholesterolemia, type 2 diabetes, weight gain, prostatic hyperplasia, gout, osteoarthritis and respiratory diseases. A review [42] is based on the several papers related to this wide-ranging study; some of such documents are quoted herein [43]-[46]. In most cases, the extent of the benefits is related to the intensity of the physical activity.

A R reduction for kidney $\mathrm{C}$ up to $76 \%$ has been observed in the most active athletes, compared to inactive people. In fact, physical activity may, e.g. prevent weight and blood pressure increase, and decrease estrogen and insulin; these are all known R factors for kidney C [43].

A R reduction up to $50 \%$ for cataract is attributed to cardiorespiratory fitness and lower body mass index [44].

A R reduction of 54\% or more for glaucoma has been observed in very active athletes. High intraocular pressure, an important $\mathrm{R}$ factor for glaucoma, is decreased through aerobic exercise proportionally to its duration and intensity; running as well as heavy work that requires exertion are beneficial in this regard [45].

A $\mathrm{R}$ reduction up to $54 \%$ in the incidence of macular degeneration is associated with the higher doses of vigorous exercise [46].

A moderate physical activity may help in the prevention of cartilage degeneration, whereas an excess or an insufficient physical activity may result in a loss of cartilage in the knees.

In people at R for osteoarthritis, the low impact sports such as swimming and walking, are more likely to provide benefits than the high impact ones such as tennis or running [47].

In people with osteoarthritis, low impact physical activity practiced with moderation improves the quality of life of without worsening the severity of the disease [48].

A document deals with bones; the link "Exercise, Nutrition" deals with the difference in bone density of spine, hip, arm and leg, between athletes and those who are not sportsmen. The link also provides information about the calcium content of several foods [49].

Athletes involved in high load activities, compared to controls, exhibited a 10\% - 20\% higher bone mineral density. Interestingly, in professional tennis players the bone mineral content of the dominant arm, compared to the other one, is $25 \%$ - $35 \%$ higher.

Malnutrition and excess of physical activity may lead to a reduced bone mineral content [50]. A 10\% decrease in bone mineral density is associated with a doubled fracture $\mathrm{R}$ [50].

The mechanical loading and the consequent slight deformations that occur in our bones during vigorous exercise, activate the osteocytes, which are stellated cells embedded within the calcified bone matrix. The activation results in the production of signalling molecules that regulate the activity of other cells: the bone-forming osteoblasts and the bone-resorbing osteoclasts [51]. The presence of mechanical stimuli leads to bone formation, whereas their absence results in bone resorption. The gain or loss of bone mass is consequent to such processes [51].

A document of WHO focuses on the importance of physical activity in the prevention of osteoporosis, a disease related to a reduced bone mineral density. This disease entails higher fracture $\mathrm{R}$, back pain and loss of height [52].

Several exercises, e.g. load-bearing or stair-climbing, contribute to strengthen the bones. Regular exercise improves coordination and strengthens muscles, thus decreasing the R of falling [52]. Exercise during childhood is of the utmost importance to maximize bone mineral density, and continuing physical activity during adulthood minimises bone loss, thus contributing to preventing osteoporosis later in life [52]. Bones, similarly to the muscles, become bigger and stronger as a response to stress; but this last should not be extremely heavy on bones and joints [52].

Among the aims of "International Walk to School" there is the promotion of physical activity, through walking safely to school, and awareness about the possibilities of creating walkable communities [53]. The website of this organisation allows us to contact its coordinators in the diverse countries as well as to open the link of "National Center for Safe Routes to School".

A report of CDC deals with the association between the academic performances and the physical activity, also including walking to school [54]. Physical activity may reduce anxiety and stress, improve self esteem, academic behaviour and academic achievement, in addition, it is linked with lower dropout rates [54]. 


\subsection{Smoking}

Tobacco use, besides being associated with an increased $R$ of lung $C$, is also strongly linked to $C R$ in several other sites of the human body. A graph contained in a document of the American Cancer Society shows the annual number of deaths caused by $\mathrm{C}$ attributable to smoking, for each site of the body [55]. In particular, we can observe the strong contribution of tobacco to increasing the Rs of $\mathrm{C}$ of esophagus, larynx and oropharynx.

A WHO document provides further information on the subject [56]. In developed countries, smoking increases the $R$ of lung $C 5$ to 10 times. Carcinogenic polyaromatic hydrocarbons are likely to be absorbed into the blood and transported to parts of the body not directly exposed to the smoke, such as bladder and pancreas [56]. Among males, the rates of oral and laryngeal Cs are respectively 27 and 12 times higher for smokers compared to non-smokers [56]. The $\mathrm{R}$ of colon $\mathrm{C}$ is increased among smokers, this is attributed to carcinogens present in the smoke that arrive to the colon after having been inhaled or swallowed [56].

An image shows the points of the human body where smoking is known to cause C [57].

Smoking may damage our DNA thus leading to $C$, in addition, may hinder the ability of our immune system to attack and kill cancerous cells. For this reason smoke may nullify the benefits of chemiotherapy in people that already have C [57].

A report of the US Surgeon General provides much information about, e.g. the chemicals that tobacco smoke contains, nicotine addiction, relations of smoking with diabetes, C, damage to arteries, lungs and children [57].

The blood becomes very sticky as a consequence of chemical alterations induced by smoking, thus increasing the likelihood of clot formation and blockage of the flow to brain, heart or other parts of the body [57]. The chemicals of tobacco smoke can hinder the ability to repair damages in the lining of the arteries, thus increasing the $\mathrm{R}$ of clot formation. Smoking may cause in the arteries a plaque buildup, whose rupture may also result in clots formation and arteries blockage. The $\mathrm{R}$ of stroke and heart attack is increased; however, the $\mathrm{R}$ of this last may fall to about the same level of a nonsmoker within 2 - 5 years after smoking cessation [57].

Smoking can also damage DNA in the sperm of the man, with negative consequences for reproduction [57]. The chemicals present in the smoke alter the functioning of the tubes where the eggs travel on their way to the womb, thus affecting fertility and pregnancy. Both smoking and breathing second hand smoke are dangerous for pregnant women [57].

Smoking reduces the ability of the walls between the air sacs in the lungs to stretch and shrink back, thus making difficult the exchange of air [57].

More than 300,000 children in the US suffer from infections caused by second hand smoke.

Smoking increases both the $\mathrm{R}$ to have type 2 diabetes and the severity of this disease. After smoking cessation, among other benefits, diabetics have a better control of their plasmatic glucose [57].

The document provides information about smoking cessation and contains a link, www.smokefree.gov, that allows us to read more on the subject and the benefits of quitting; it also contains quizzes and a quit plan [57].

Studying the consequences of smoking on bone health is not simple because of the several $\mathrm{R}$ factors common among smokers. However, recent studies have shown a reduction in bone density directly related to tobacco use and many studies, but not all, suggest that smoking increases the R of fractures [58].

A document summarizes the health effects of cigarette smoking, and the benefits of quitting over time; for instance, within 5 years a drop by half has been observed in the $R$ of $C$ in: mouth, throat, bladder and exophagus [59].

\subsection{Alcohol Drinking}

A meta-analysis has studied the relations between alcohol drinking and R of C in several sites of the body [60]. The results of this study can be clearly observed in tables and graphs contained in the document. The R of C grows as the daily alcohol intake increases.

The relative Rs associated with an alcohol intake of $100 \mathrm{~g} /$ day are: 6.0 for oral cavity and pharynx, 4.2 for oesophagus, 3.9 for larynx and 2.7 for breast; people without such exposure are assigned a R of 1.0 [60].

A page of National Cancer Institute explains, inter alia, how alcohol drinking increases the R of C [61]. Alcohol raises the blood level of estrogen; this is linked with an increased $\mathrm{R}$ of breast C [61]. The acetaldehyde produced by the metabolism of alcohol is considered a probable human carcinogen and can damage the DNA. Acetaldehyde may cause inflammation to the pancreas; this is a $\mathrm{R}$ factor for pancreatic C [61] [62]. For genetic reasons, in some people of east Asian origin, alcohol drinking results in an excess acetaldehyde buildup and 
leads to unpleasant effects and increased R of C [61].

Two papers [62] [63] deal with the negative effect of alcohol on brain, heart, liver, pancreas, immune system and C Rs.

Chronic use of alcohol is also associated with higher $\mathrm{R}$ of fractures, consequent to both an altered calcium balance and an increased likelihood of falls [58].

Low amounts of alcohol may provide benefits to several categories of people, lowering, e.g. blood pressure, cholesterol, and Rs of clot formation, stroke, heart attack.

It is generally suggested that a safe amount of alcohol intake should not exceed two drinks a day for men, and one for women [63]. However, children and teens, as well as people involved in activities that require skill, coordination and attention should not drink alcohol at all [19]. Pregnant women, those who take certain medications or with a medical condition, and recovering alcoholics are among the categories of people that should not drink alcohol at all [62] [63].

According to a US document, alcohol abuse is also involved in one third of violent crimes and in 16,000 deadly automobile accidents each year. The cost of alcohol abuse is 185 billion dollars a year [63].

A document of the National Institute on Alcohol Abuse and Alcoholism is dedicated to underage drinking in the US [64]. The document deals with the diffusion among young people of both binge and heavy drinking, the Rs that it entails, and how its signs can be recognised. Through a link it is possible to read more on it and in particular on its prevention [64].

\section{Combined Exposure to Smoking and Alcohol Drinking}

The combined exposure to smoke and alcohol has a greater effect than the simple sum of each agent alone.

A study deals, inter alia, with the relative $\mathrm{R}$ of $\mathrm{C}$ of the glottis in people that were simultaneously:

- both moderate drinkers and smokers;

- moderate drinkers and heavy smokers;

- heavy drinkers and moderate smokers;

- both heavy drinkers and smokers.

Such Rs are respectively 1, 19.2, 5.1 and 289.4 [65].

It has been hypothesized that alcohol might act as a solvent that transports the carcinogenic substances contained in tobacco smoke, thus implying a multiplicative effect of the Rs [65].

A review deals with the $\mathrm{R}$ of $\mathrm{C}$ in the upper aerodigestive tract, so directly exposed to smoking and alcohol consumption [66]. A study has found that the Rs of oral and pharyngeal C are 300 times higher in people that smoked and drank heavily, compared to those that neither smoked nor drank [66]. The paper also deals with the strongly increased Rs consequent to the combined effect of heavily drinking and smoking concerning the laryngeal and esophageal Cs [66].

As far as this last is concerned, for a more complete information, it must be said that gastroesophageal reflux is a condition that may irritate the esophagus and over time may also lead to an increased C R. This R is also increased by: overeating that leads to obesity, drinking very hot liquids, a diet rich in processed meat. A diet rich with yellow and green vegetables, fruits, and cruciferous vegetables in particular constitute a protective factor for the esophagus [67] [68].

A page of the American Cancer Society contains quizzes: about some common Cs, quitting smoking, sun safety, nutrition and activity [69].

\section{Conclusion}

According to a personal experience, the use of these educational resources helps teachers in teaching and students in learning about cancer prevention.

\section{Acknowledgements}

The author would like to thank Dr. Liu Lin for information kindly provided.

\section{References}

[1] World Health Organisation (2015) Cancer. http://www.who.int/mediacentre/factsheets/fs297/en/ 
[2] World Health Organisation (2003) Diet, Nutrition and the Prevention of Chronic Diseases. http://whqlibdoc.who.int/trs/WHO_TRS_916.pdf?ua=1

[3] Marrocco, A. (2015) Online Educational Resources Regarding Cardiovascular Prevention. E-Health Telecommunication Systems and Networks, 4, 10-21. http://dx.doi.org/10.4236/etsn.2015.41002

[4] Cornell University Library (2012) Evaluating Web Sites: Criteria and Tools. http://olinuris.library.cornell.edu/ref/research/webeval.html

[5] Jemal, A., et al. (2010) Global Patterns of Cancer Incidence and Mortality Rates and Trends. http://cebp.aacrjournals.org/content/19/8/1893.full

[6] World Health Organisation (2015) Cancer, Early Detection. http://www.who.int/cancer/en/

[7] Jemal, A.,et al. (2011) Global Cancer Statistics. http://onlinelibrary.wiley.com/doi/10.3322/caac.20107/full http://dx.doi.org/10.3322/caac.20107

[8] International Agency for Research on Cancer (2015) All Cancers Estimated Incidence, Mortality and Prevalence Worldwide in 2012. http://globocan.iarc.fr/Pages/fact sheets cancer.aspx

[9] Pulitzer Center. Cancer’s Global Footprint. http://globalcancermap.com/

[10] Jemal, A. and Ward, E. (2015) International Trends in Colorectal Cancer. http://cebp.aacrjournals.org/content/18/6/1688.full

[11] John, E.M., Phipps, A.I., Davis, A. and Koo, J. (2005) Migration History, Acculturation, and Breast Cancer Risk in Hispanic Women. http://cebp.aacrjournals.org/content/14/12/2905.long

[12] Lee, J., Demissie, K., Lu, S.-E. and Rhoads, G.G. (2007) Cancer Incidence among Korean-American Immigrants in the United States and Native Koreans in South Korea.

http://moffitt.org/File\%20Library/Main\%20Nav/Research\%20and\%20Clinical\%20Trials/Cancer\%20Control\%20Journ al/v14n1/78.pdf

[13] McCormack, V.A. and Boffetta, P. (2011) Today’s Lifestyles, Tomorrow’s Cancers: Trends in Lifestyle Risk Factors for Cancer in Low- and Middle-Income Countries. http://annonc.oxfordjournals.org/content/22/11/2349.long http://dx.doi.org/10.1093/annonc/mdq763

[14] Pukkala, E., Martinsen, J.I., Lynge, E., Gunnarsdottir, H.K., Sparén, P., Tryggvadottir, L., et al. (2009) Occupation and Cancer-Follow-Up of 15 Million People in Five Nordic Countries. http://informahealthcare.com/doi/pdfplus/10.1080/02841860902913546

[15] American Cancer Society (2015) Infectious Agents. http://www.cancer.org/cancer/cancercauses/othercarcinogens/infectiousagents/index

[16] American Cancer Society (2015) Family Cancer Syndromes. http://www.cancer.org/cancer/cancercauses/geneticsandcancer/heredity-and-cancer

[17] National Cancer Institute (2013) Genetic Testing for Hereditary Cancer Syndromes. http://www.cancer.gov/cancertopics/genetics/genetic-testing-fact-sheet

[18] National Cancer Institute. http://www.cancer.gov/

[19] American Cancer Society (2015) ACS Guidelines on Nutrition and Physical Activity for Cancer Prevention. http://www.cancer.org/healthy/eathealthygetactive/acsguidelinesonnutritionphysicalactivityforcancerprevention/nupa-g uidelines-toc

[20] American Cancer Society (2015) Learn about Cancer. http://www.cancer.org/cancer/index

[21] National Cancer Institute. Causes and Prevention. http://www.cancer.gov/cancertopics/causes

[22] International Agency for Research on Cancer (2015) Monographs and Supplements. http://monographs.iarc.fr/ENG/Monographs/PDFs/index.php

[23] Block, G., Patterson, B. and Subar, A. (2009) Fruit, Vegetables and Cancer Prevention: A Review of the Epidemiological Evidence. http://www.tandfonline.com/doi/pdf/10.1080/01635589209514201

[24] Zhang, S.M., Willett, W.C., Selhub, J., Hunter, D.J., Giovannucci, E.L., Holmes, M.D., Colditz, G.A. and Hankinson, S.E. (2003) Plasma Folate, Vitamin $B_{6}$, Vitamin $B_{12}$, Homocysteine, and Risk of Breast Cancer.

http://jnci.oxfordjournals.org/content/95/5/373.long http://dx.doi.org/10.1093/jnci/95.5.373

[25] World Health Organisation (2015) Promoting Fruit and Vegetable Consumption around the World. http://www.who.int/dietphysicalactivity/fruit/en/index2.html

[26] Norat, T., Bingham, S., Ferrari, P., Slimani, N., Jenab, M., Mazuir, M., et al. (2005) Meat, Fish, and Colorectal Cancer Risk: The European Prospective Investigation into Cancer and Nutrition.

http://jnci.oxfordjournals.org/content/97/12/906.full 
http://dx.doi.org/10.1093/jnci/dji164

[27] American Heart Association (2015) Fish and Omega-3 Fatty Acids. http://www.heart.org/HEARTORG/GettingHealthy/NutritionCenter/HealthyDietGoals/Fish-and-Omega-3-Fatty-Acids _UCM_303248_Article.jsp

[28] Sengupta, A., Ghosh, S. and Bhattacharjee, S. (2004) Allium Vegetables in Cancer Prevention: An Overview. http://www.apocpcontrol.org/paper_file/issue_abs/Volume5_No3/Archana\%20Sengupta.pdf

[29] National Cancer Institute. http://www.cancer.gov/about-cancer/causes-prevention/risk/diet

[30] He, F.G., Nowson, C.A., Lucas, M. and MacGregor, G.A. (2007) Increased Consumption of Fruit and Vegetables Is Related to a Reduced Risk of Coronary Hearth Disease: Meta-Analysis of Cohort Studies. http://www.nature.com/jhh/journal/v21/n9/full/1002212a.html

[31] Williams, F.M.K., Skinner, J., Spector, T.D., Cassidy, A., Clark, I.M., Davidson, R.M. and MacGregor, A.J. (2010) Dietary Garlic and Hip Osteoarthritis: Evidence of a Protective Effect and Putative Mechanism of Action. http://www.ncbi.nlm.nih.gov/pmc/articles/PMC3018463/ http://dx.doi.org/10.1186/1471-2474-11-280

[32] FAO (2005) Setting up and Running a Scholar Garden. http://www.unicef.org/education/files/How_to_Set_up_School_Garden.pdf

[33] Waseem, A., Arshad, J., Iqbal, F., Sajjad, A., Mehmood, Z. and Murtaza, G. (2014) Pollution Status of Pakistan: A Retrospective Review on Heavy Metal Contamination of Water, Soil, and Vegetables. http://www.hindawi.com/journals/bmri/2014/813206/ http://dx.doi.org/10.1155/2014/813206

[34] World Health Organisation (2012) Five Keys to Growing Safer Fruits and Vegetables: Promoting Health by Decreasing Microbial Contamination. http://apps.who.int/iris/bitstream/10665/75196/1/9789241504003 eng.pdf

[35] University of Wisconsin-Extension (2007) Safely Using Produce from Flooded Gardens. https://www.foodsafety.wisc.edu/assets/pdf Files/Safely\%20Using\%20Produce\%20from\%20Flooded\%20Gardens.pdf

[36] University of California (2010) Home Gardens and Lead. What You Should Know about Growing Plants in LeadContaminated Soil. http://anrcatalog.ucdavis.edu/pdf/8424.pdf

[37] National Cancer Institute. Obesity and Cancer Risk. http://www.cancer.gov/cancertopics/causes-prevention/risk/obesity/obesity-fact-sheet

[38] Grotle, M., Hagen, K.B., Natvig, B., Dahl, F.A. and Kvien, T.K. (2008) Obesity and Osteoarthritis in Knee, Hip and/or Hand: An Epidemiological Study in the General Population with 10 Years Follow-Up. http://www.ncbi.nlm.nih.gov/pmc/articles/PMC2573886/ http://dx.doi.org/10.1186/1471-2474-9-132

[39] Cheung, N. and Wong, T.Y. (2009) Obesity and Eye Diseases. http://www.ncbi.nlm.nih.gov/pmc/articles/PMC2698026/

[40] Harvard School of Public Health (2015) Obesity Prevention Source. http://www.hsph.harvard.edu/obesity-prevention-source/

[41] Carpenter, C.L., Ross, R.K., Paganini-Hill, A. and Bernstein, L. (1999) Lifetime Exercise Activity and Breast Cancer Risk among Post-Menopausal Women. http://www.ncbi.nlm.nih.gov/pmc/articles/PMC2374273/pdf/80-6690610a.pdf

[42] Edison, G.W. (2014) Physical Activity and Its Effect on Reducing Disease: A Literature Review of The National Runner's Health Study. http://trace.tennessee.edu/cgi/viewcontent.cgi?article=2781\&context=utk chanhonoproj

[43] Williams, P.T. (2013) Reduced Risk of Incident Kidney Cancer from Walking and Running. http://www.ncbi.nlm.nih.gov/pmc/articles/PMC4067489/

[44] Williams, P.T. (2008) Prospective Epidemiological Cohort Study of Reduced Risk for Incident Cataract with Vigorous Physical Activity and Cardiorespiratory Fitness during a 7-Year Follow-Up. http://www.ncbi.nlm.nih.gov/pmc/articles/PMC4108287/

[45] Williams, P.T. (2009) Relationship of Incident Glaucoma versus Physical Activity and Fitness in Male Runners. http://www.ncbi.nlm.nih.gov/pmc/articles/PMC2864610/

[46] Williams, P.T. (2008) Prospective Study of Incident Age-Related Macular Degeneration in Relation to Vigorous Physical Activity during a 7-Year Follow-Up. http://www.ncbi.nlm.nih.gov/pmc/articles/PMC4090325/

[47] UCSF (2012) Preventing Osteoarthritis: How Much Exercise Is Just Right? https://www.ucsf.edu/news/2012/11/13209/preventing-osteoarthritis-how-much-exercise-just-right

[48] Centers for Diseases Control and Prevention. Physical Activity and Osteoarthritis Overview. http://www.cdc.gov/arthritis/pa_overview.htm 
[49] ASBMR (2008) Bone Curriculum. Educational Resource Materials by the American Society for Bone and Mineral Research. https://depts.washington.edu/bonebio/ASBMRed/ASBMRed.html

[50] Karlsson, M.K., Nordqvist, A. and Karlsson, C. (2008) Physical Activity Increases Bone Mass during Growth. http://www.ncbi.nlm.nih.gov/pmc/articles/PMC2596740/

[51] Nulend, J.K., Bacabac, R.G. and Bakker, A.D. (2012) Mechanical Loading and How It Affects Bone Cells: The Role of the Osteocyte Cytoskeleton in Maintaining Our Skeleton. http://www.ecmjournal.org/journal/papers/vol024/pdf/v024a20.pdf

[52] Chan, K.M., Anderson, M. and Lau, E.M.C. (2003) Exercise Interventions: Defusing the World’s Osteoporosis Time Bomb. http://www.who.int/bulletin/volumes/81/11/mingchanwa1103.pdf

[53] iwalk: The Official Website of International Walk to School. http://www.iwalktoschool.org/

[54] U.S. Department of Health and Human Services (2010) The Association between School-Based Physical Activity, Including Physical Education, and Academic Performance.

http://www.cdc.gov/HealthyYouth/health_and_academics/pdf/pa-pe_paper.pdf

[55] American Cancer Society (2006) Cancer Facts \& Figures 2006. http://www.cancer.org/acs/groups/content/@nho/documents/document/caff2006pwsecuredpdf.pdf

[56] World Health Organisation (2015) Tobacco Free Initiative. Cancer. http://www.who.int/tobacco/research/cancer/en/

[57] U.S. Department of Health and Human Services (2010) How Tobacco Smoke Causes Disease. http://www.cdc.gov/tobacco/data_statistics/sgr/2010/consumer_booklet/pdfs/consumer.pdf

[58] National Institute of Arthritis and Musculoskeletal and Skin Diseases (2012) Smoking and Bone Health. http://www.niams.nih.gov/health_info/bone/Osteoporosis/conditions_Behaviors/bone_smoking.asp

[59] Centers for Disease Control and Prevention (2014) Health Effects of Cigarette Smoking. http://www.cdc.gov/tobacco/data_statistics/fact_sheets/health_effects/effects_cig_smoking/

[60] Bagnardi, V., Blangiardo, M., La Vecchia, C. and Corrao, G. (2001) A Meta-Analysis of Alcohol Drinking and Cancer Risk. http://www.ncbi.nlm.nih.gov/pmc/articles/PMC2363992/pdf/85-6692140a.pdf

[61] National Cancer Institute (2013) Alcohol and Cancer Risk. http://www.cancer.gov/cancertopics/causes-prevention/risk/alcohol/alcohol-fact-sheet

[62] National Institute on Alcohol Abuse and Alcoholism (2010) Understanding Alcohol’s Impact on Your Health. http://pubs.niaaa.nih.gov/publications/Hangovers/beyondHangovers.pdf

[63] Harvard School of Public Health (2015) Alcohol: Balancing Risks and Benefits. http://www.hsph.harvard.edu/nutritionsource/alcohol-full-story/

[64] National Institute on Alcohol Abuse and Alcoholism. Underage Drinking. http://www.niaaa.nih.gov/alcohol-health/special-populations-co-occurring-disorders/underage-drinking

[65] Guenel, P., Chastang, J.F., Luce, D., Leclerc, A. and Brugère, J. (1988) A Study of the Interaction of Alcohol Drinking and Tobacco Smoking among French Cases of Laryngeal Cancer. http://www.ncbi.nlm.nih.gov/pmc/articles/PMC1052764/

[66] Pelucchi, C., Gallus, S., Garavello, W., Bosetti, C. and La Vecchia, C. (2006) Cancer Risk Associated with Alcohol and Tobacco Use: Focus on Upper Aerodigestive Tract and Liver. http://pubs.niaaa.nih.gov/publications/arh293/193-198.pdf

[67] National Cancer Institute (2013) Esophageal Cancer Prevention. http://www.cancer.gov/types/esophageal/patient/esophageal-prevention-pdq

[68] American Cancer Society (2015) What Are the Risk Factors for Cancer of the Esophagus? http://www.cancer.org/cancer/esophaguscancer/detailedguide/esophagus-cancer-risk-factors

[69] American Cancer Society (2015) Quizzes. http://www.cancer.org/healthy/toolsandcalculators/quizzes/index 